\title{
Yerel Jeoit Belirlemede Yapay Sinir Ağlarının Farklı Nokta Yoğunluğundaki Performansı
}

\author{
Performance of Artificial Neural Networks on Different Point Density in Local Geoid \\ Determination
}

\author{
Yaşar FİDANCI*a, Ramazan Alpay ABBAK ${ }^{\mathrm{b}}$ \\ Konya Teknik Üniversitesi, Mühendislik ve Doğa Bilimleri Fakültesi, Harita Mühendisliği Bölümü, 42075, Selçuklu, Konya
}

• Geliş tarihi / Received: 24.12.2018 • Düzeltilerek geliş tarihi / Received in revised form: 04.03.2019 • Kabul tarihi / Accepted: 12.03 .2019

\begin{abstract}
$\ddot{O} z$
Jeoit, fiziksel anlamlı ortometrik yükseklikler için referans yüzeyidir. Bu nedenle jeoidin yüksek hassasiyette belirlenmesi yerbilimlerinde özellikle jeodezide hayati öneme sahiptir. Uygulamada jeoit belirleme için çoğunlukla GNSS (Global Navigation Satellite Systems-Küresel Seyrüsefer Uydu Sistemleri) ve nivelman verilerini birlikte değerlendiren birçok matematiksel yüzey ve enterpolasyon teknikleri uygulayan geometrik yöntem kullanılır. Günümüzde hızla gelişen yapay zekâ ve makine öğrenmesi teknolojileri, algoritması çok karışık problemlere insan beyni gibi davranarak çözümler üretmektedir. Bu çalışmada yapay zeka teknolojilerinden yapay sinir ağı incelenmiş, jeoit belirlemede kullanılabilirliği test edilmiştir. Bu amaçla yaklaşık $2765 \mathrm{~km}^{2}$ lik yüzölçümüne sahip bir çalışma alanı seçilmiş ve bu alanda bulunan 326 GNSS-nivelman noktası aracılığ 1 ile eğitim ve test verilerini değiştirerek 6 adet deney yapılmıştır. $\mathrm{Bu}$ noktalar çeşitli kombinasyonlar oluşturacak şekilde eğitim ve test seti olarak ayrılmıştır. $\mathrm{Bu}$ bağlamda yapay sinir ağı modelleri ve polinomal eğri yüzey modelleri oluşturulmuş ve karşılaştırma sonuçları üretilmiştir. Sayısal sonuçlar "Büyük Ölçekli Harita ve Harita Bilgileri Üretim Yönetmeliği” açısından bakıldığında homojen hem de homojen olmayan nokta dağılımında yapay sinir ağı modelinin polinomal yüzey modelinden daha iyi sonuçlar ürettiği görülmüştür.
\end{abstract}

Anahtar kelimeler: Çok Katmanlı Algılayıcılar, Jeoit Belirleme, Polinomal Eğri Yüzey Uydurma, Yapay Sinir Ağları

\begin{abstract}
Geoid is a reference surface for physical orthometric heights. Thus precise geoid determination is essential important in geosciences especially in geodesy. For the geoid determination the geometrical method that evaluates GNSS (Global Navigation Satellite Systems) together with levelling data is mostly used in practice. In order to determine geoid surface, many mathematical surfaces and interpolation techniques are applied in this method. Today the rapidly developing artificial intelligence and machine learning technologies by behaving the human brain produce solutions to problems, which have very complex algorithms. In this study, the artificial neural network from artificial intelligence technologies was examined and also its usability was tested in the geoid determination. For this purpose, a study area that covers approximately $2765 \mathrm{~km}^{2}$ was selected and some tests were carried out in this area by using 326 GNSSlevelling points. These points were divided into training and test datasets in order to create various combinations. In this context, some artificial neural network models and polynomial curve surface models were yielded and comparison results were produced. According to numerical results, it was observed that models of artificial neural networks produced better results than the polynomial curve surface models in the homogenous and non-homogeneous point distributions from viewpoint of "Rules of Large Scale Map and Map Data Production".
\end{abstract}

Keywords: Multilayer sensors, Geoid Determination, Polynomial Curve Surface Fitting, Artificial Neural Networks

\footnotetext{
*a Yaşar FIDANCI, yasar.fidanci@gmail.com, Tel: (542) 339 7372; orcid.org/0000-0001-7642-5257

${ }^{\mathrm{b}}$ orcid.org/0000-0002-6944-5329
} 


\section{Giriş}

Fiziksel jeodezinin amac1 gravite alanı ve onun eşpotansiyel yüzeylerinden biri olan jeoidin belirlenmesidir. Jeoit matematiksel olarak ifade edilemeyen belirli bir model veya algoritma ile kesin olarak açılanamayan bir yüzey olarak tanımlanabilir. Yüksekliğin referans yüzeyi olduğu için jeoit jeodeziciler için hayati öneme sahiptir.

Yükseklik kavramını en yalın haliyle tanımlamak gerekirse bir noktanın başlangıç yüzeyiyle ilişkisi olarak anlaşılır. Bu ilişki yalnızca fiziksel, ya da geometrik olabileceği gibi hem fiziksel kem geometrik de olabilir. Ancak mühendislik uygulamalarından fiziksel yükseklik sistemleri kullanılmaktadır. Bunun nedeni akışkanların hareket yönü doğrudan gravite alanı ile ilişkili olmasıdır. Başka bir deyişle altyapı ve mühendislik hizmetlerinin doğru bir şekilde gerçekleşebilmesi için gravite alanı ile ilişkili yükseklik sistemleri kullanılmalıdır (Abbak, 2017).

Gelişen teknolojilerle birlikte GNSS (Global Navigation Satellite Systems-Küresel Seyrüsefer Uydu Sistemleri) ortaya çıkmış ve bu sistemlerle birlikte yüksek doğrulukta konum bilgileri elde edilmeye başlanmıştır. GNSS sistemlerinin sağladığ1 yükseklik bilgisi mühendislik uygulamalarında ihtiyaç duyulan türden bir fiziksel yükseklik olmayıp geometrik anlam içermektedir. Geometrik yüksseklikten $h$ fiziksel yüksekliğe $H$ geçiş

$H=h-N$

eşitliği sağlanabilmektedir (Şekil 1).

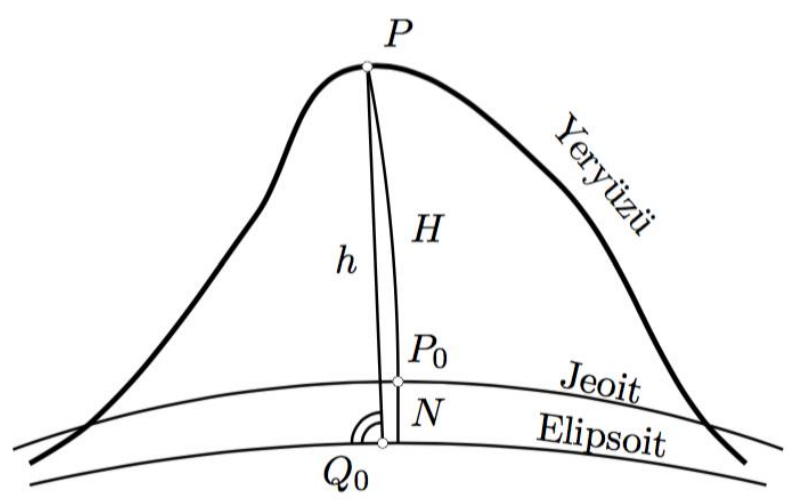

Şekil 1. Ortometrik ve elipsoidal yükseklik arasındaki ilişki (Abbak, 2017)

Buradaki en önemli husus $N$ jeoit yüksekliğinin (jeoidin) belirlenmesidir.
Yüksek doğruluklu jeoit belirleme çalışmaları halen günümüzde araştırma konularının başında gelmektedir. Jeoit yüzeyini modellemek için birçok yüzey ve enterpolasyon yöntemleri uygulanmış ve bu matematiksel yöntemlerle jeoit yüzeyi gerçeğe en yakın şekilde modellenmeye çalışılmıştır. Şimdiye kadar yapılan çalışmalar kısaca; polinomal, enterpolasyon, sonlu elemanlar, kollokasyon, bulanık çıkarımlar olarak siralanabilir.

$\mathrm{Bu}$ yöntemlere ek olarak gelişen yapay zekâ teknolojisiyle makine öğrenmeleri yapılabildiği, makinelerin insanların beyin fonksiyonlarını taklit ederek olaylar arasında sebep sonuç ilişkisi kurabildiği görülmüsstür. Dahası girdilerden yola ç1karak öngörü ve tahminler yapabilmektedir. Ayrıca değişen şartlar altında öğrenme devam etmekte ve yeni duruma kendilerini adapte edebilmektedir. $\mathrm{Bu}$ teknolojiden faydalanılarak yukarıda bahsettiğimiz gibi jeoit yüksekliğinin yüksek doğrulukta tahmin edilmesi yerin fiziksel anlamlı yüksekliklerinin bilinmesinde çok büyük önem arz etmektedir.

Literatürde birçok çalışmada makine öğrenmesi ve yapay zekâ teknolojileri kullanılarak jeoit belirleme üzerine çalışmalar yapılmıştır. Çalışmalar genel olarak yüzey uydurma ve enterpolasyon yöntemleri ile bu yöntemlere alternatif olabilecek yapay zekâ teknolojilerinin ürettiği modelin sonuçlarının karşılaştırılması niteliğindedir. Çorumluoğlu vd. (2005), yapay sinir ağları yardımı ile ortometrik yükseklikler elde edilmiş, test verilerinin standart sapmasının Büyük Ölçekli Harita ve Harita Bilgileri Üretim Yönetmeliği (BÖHHBÜY) sınırları içinde kaldığını göstermiştir. $\mathrm{Bu}$ çalışma jeoit belirlemede yapay sinir ağlarının etkin bir şekilde kullanılabileceği sonucuna varmıştır. Arslan vd. (2007), yapay sinir ağları ile polinomal eğri yüzey uydurma yöntemlerini analiz etmiş ve yapay sinir ağlarının daha başarılı sonuç ürettiği sonucuna varılmış. Aşık (2013), yapay sinir ağları ile Kriging yöntemi kıyaslanmış yapay sinir ağının çok daha iyi sonuç ürettiğini göstermiştir. Çakır (2015) ise ileri beslemeli yapay sinir ağları, bulanık mantık çıkarımı, polinomal yüzey uydurma ve multikuadrik enterpolasyon yöntemleri karşılaştırılmış; yapay sinir ağları ve bulanık çıkartımın, polinomal ve multikuadrik yöntemden daha iyi sonuç verdiği sonucuna varmıştır.

Bu çalışmada, Belçika'nın kuzeydoğu bölgesinde çalışma alanı seçilerek yapay zekâ teknolojisi makine öğrenmesi ile jeoit yükseklikleri tahmin 
edilecek ve elde edilen sonuçlar polinomal yöntemle karşılaştırılarak irdelenecektir. Makine öğrenme teknolojilerinden ileri beslemeli hata geri yayılımlı yapay sinir ağları ile polinomal eğri yüzey uydurma yöntemi ile karşılaştırılmış eğitim nokta verileri kademeli olarak azaltılarak modellerin nasıl etkilendiği irdelenmiş, ayrıca homojen ve homojen olmayan nokta dağılımında yöntemlerin ürettiği modellerin doğruluğu araştırılmıştır. Son olarak yapay sinir ağlarının gündelik kullanımına yönelik görüş ve öneriler sunulmuştur.

\section{Yöntem}

\subsection{Yapay Sinir Ağlart}

Yapay sinir ağları insan beyninin özelliklerinden olan öğrenme yoluyla yeni bilgi türetme, yeni bilgiler oluşturabilme ve keşfetme gibi yetenekleri herhangi bir yardım almadan otomatik olarak gerçekleştirmek amacıyla geliştirilen bilgisayar sistemleridir (Öztemel, 2016). Daha genel bir tanım yapmak gerekirse insan beyninin öğrenmeyi sağlayan sinir hücrelerini model alarak örnek olayları ve sonuçlarını kullanarak öğrenebilen ve çevresel etkilere karş1 üretilecek tepkileri belirleyen bilgisayar sistemi olduğu söylenebilir.

Yapay sinir ağlarının kullanım amacı herhangi matematiksel modelle tasvir edilemeyen bir problemi veya çok karmaşık algoritmalara sahip problemlerin çözümüdür. Dolayısı ile çevreden gelen etkileri okuyabilen bu etkilerle öğrenen ve bu etkilere tepki veren sistemlerdir. İnsan beyninin fonksiyonel özelliklerine benzer şekilde; öğrenme, ilişkilendirme, sınıflandırma, genelleme, optimizasyon görevlerini başarıyla yapmaktadır.

Teknik olarak da yapay sinir ağlarının en temel görevi, kendisine gösterilen örneklere karşıllk gelebilecek bir sonuç belirlemektir. Bunu yapabilmesi için, yapay sinir ağının örnekler ile eğitilerek genelleme yapabilecek yeteneğe kavuşturulur. $\mathrm{Bu}$ genelleme ile benzer olaylara karşıllık gelen çıktı setleri belirlenir (Öztemel, 2016).

Yapay sinir ağları ile nelerin yapılabileceği konusunda bir sınırlama yapmak çok zordur. Genel olarak örnek verilebilen tüm konular hakkında yapay sinir ağları kurulabilir. Çözüm aranan problemlerde yapay sinir ağları diğer çözüm yolarından daha avantajlı olduğu durumlarda tercih edilir. Yapay sinir ağları kullanırken iki maddeyi sağlaması önemlidir: sadece yapay sinir ağları ile konuya pratik çözüm üretmek mümkün mü? Başka çözüm yolları olmasına rağmen yapay sinir ağları daha pratik ve etkin bir çözüm getirebiliyor mu?

Bir yapay sinir ağında bilgileri oluşturan, bilgileri üreten, bir bilgiden başka bir bilgiyi türeten ve bu bilgileri çevren alan, ürettiği veri çıktı olarak sonuç olarak çevreye veya diğer bir proses elemanına veren mekanizma olarak tanımlayabiliriz. Yapay sinir hücreleri mühendislikte proses elemanları olarak adlandırılmaktadır (Şekil 2).

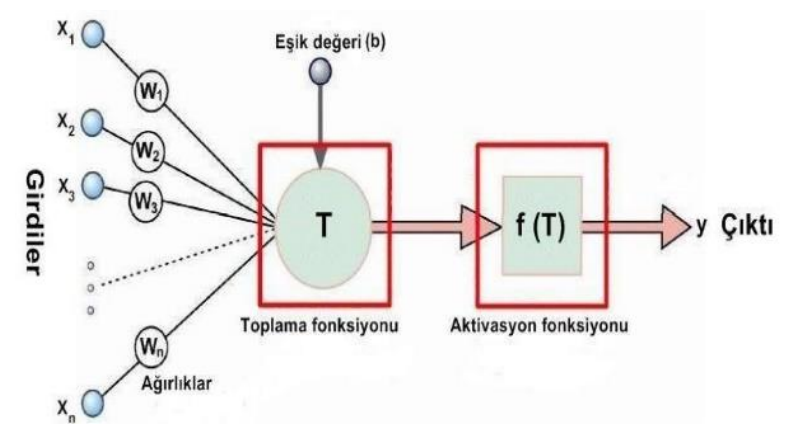

Şekil 2. Yapay sinir hücresinin yapısı (Kaftan, 2010)

Girdiler örneklerden gelen verilerdir. Bu bilgiler en temelinde dış dünyadan gelebileceği gibi başka bir proses elemanından da gelebilir. Ağırlıklar, yapay sinir hücresine giren bir bilginin önemini gösterir. Bir ağırlığın büyük veya küçük olması o verinin önemli veya önemsiz olduğunu göstermez. Ancak bir ağırlık değerinin sıfırı olması ağ için çok önem arz edebilir. Verinin ağ için bir önem etkisinin olmadığını gösterir. Ağırlıkların pozitif veya negatif olması ise o ağa sonucu pozitif veya negatif yönde etkilediğini gösterir. Eşik değer, yapay sinir ağlarında ara katman veya çıktı katmanlarının çıktı değerlerinin sıfır olmasını önlemek için kullanılır. Toplama fonksiyonu olarak adlandırılan ifade bir yapay sinir ağı hücresine giren ağırlıklandırılmış net girdinin hesaplanması için kullanılan fonksiyonları ifade eder. Yapay sinir ağlarında en yaygın olarak kullanılan fonksiyon

$N E T=\sum_{i}^{n} G_{i} A_{i}$

şeklinde ağırlıklı toplam fonksiyonudur. Aktivasyon fonksiyonu, temel hesaplama işlemini yapan ve sonucunda çıtının değerinin belirlendiği fonksiyonlardır. Aktivasyon fonksiyonunda da toplama fonksiyonu gibi temel bir formül yoktur. Yapay sinir ağlarının en yaygın olarak kullanılan modeli olan çok katmanlı algilayicılarda 
$F(N E T)=\frac{1}{1+e^{-N E T}}$

şeklinde sigmoid fonksiyon kullanılmaktadır. Buradaki NET proses elemanına giren NET girdi değeridir. Aktivasyon fonksiyonlarında da kullanımında belirli bir yöntem yoktur. Aktivasyon fonksiyonu belirlenirken yine tasarımcının kişisel öngörüsü ve deneme -yanılma yöntemi belirleyicidir. Bazı modellerde türevi alınabilir fonksiyonları şart koşmuştur. Yapay sinir ağlarında literatürde yaygın olarak kullanılan aktivasyon fonksiyonları Tablo 1'de verilmiştir (Graupe, 2007; Patan, 2008; Beale vd., 2010). Aynı aktivasyon fonksiyonlarının grafikleri Şekil 3'de gösterilmiştir.

Tablo 1. Başlıca aktivasyon fonksiyonları

\begin{tabular}{|c|c|}
\hline $\begin{array}{l}\text { Aktivasyon } \\
\text { fonksiyonun adı }\end{array}$ & Fonksiyon \\
\hline Sigmoid & $F(N E T)=\frac{1}{\left(1+e^{-N E T}\right)}$ \\
\hline $\begin{array}{l}\text { Hiperbolik } \\
\text { Tanjant }\end{array}$ & $F(N E T)=\frac{\left(e^{N E T}+e^{-N E T}\right)}{\left(e^{N E T}-e^{-N E T}\right)}$ \\
\hline Lineer & $F(N E T)=N E T$ \\
\hline Basamak & $\begin{array}{l}F(N E T) \\
=\left\{\begin{array}{l}1 E \mathrm{~g} E R N E T>E s ̧ i K D E \breve{\mathrm{g}} E R \\
0 E \breve{\mathrm{g}} E R \quad N E T<E s ̧ i K D E \breve{\mathrm{g}} E R\end{array}\right.\end{array}$ \\
\hline Gauss & $F(N E T)=e^{-\left[\frac{(N E T-C)^{2}}{\sigma^{2}}\right]}$ \\
\hline Multi Kuadratik & $F(N E T)=\frac{\sqrt{r^{2}+(N E T-C)^{2}}}{r}$ \\
\hline
\end{tabular}
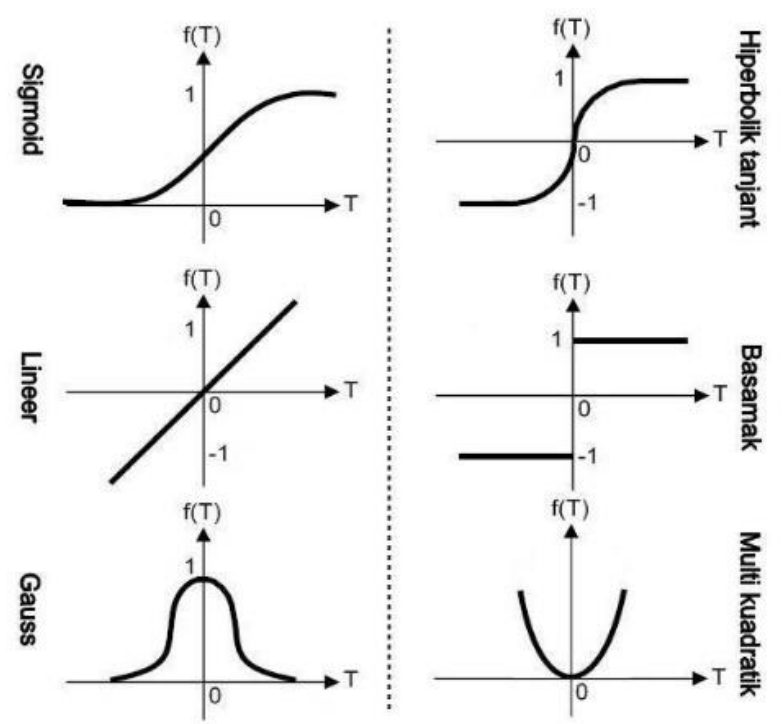

Şekil 3. Aktivasyon fonksiyonlarının grafikleri (Y1lmaz, 2012)

Çıktı, aktivasyon fonksiyonuna giren NET girdinin sonucudur. Çıktı dış dünyaya verilebile- ceği gibi başka bir proses elemanına girdi değeri olarak da sunulabilir. Bir yapay sinir hücresi bir çıktı üretebilir ancak bu çıktı birçok proses elemanına girdi olarak sunulabilir.

Yapay sinir ağlarında proses elemanlarının şekilleri kullandıkları toplama ve aktivasyon fonksiyonlarına göre, öğrenme stratejileri ve kullanım alanlarına göre farklı modeller geliştirilmiştir aşağıda yer alan modeller en yaygın olanları sunulmuştur. Bunlar; algılayıcılar, çok katmanlı algılayıcılar, vektör kuantizasyon modelleri, kendi kendini organize eden modeller, adaptif rezonans teorisi modelleridir.

Bahsedilen ağlardan çok katmanlı algılayıcılar iyi bir tahmin edici olması nedeniyle geniş olarak açılarak incelenecektir. Çok katmanlı algılayıcılar haritacılık faaliyetlerden en çok tercih edilen modellerden biridir. Kestirim özelliği sebebi ile jeoit belirlemede bu modelle çözüm aranacaktır.

Çok katmanlı algılayıcıların yapısını Şekil 4'de gösterildiği gibidir. G1, G2, ..., GN gibi girdi değerleri girdi katmanlarına girer. Girdi katmanında her bir proses elemanının bir girdi ve bir çıktı değeri vardır. Girdi katmanına giren veri herhangi bir işlem uygulanmaksızın ara katman iletilmek üzere çıkar. Bu katmanda herhangi bir işlem yapılmaz.

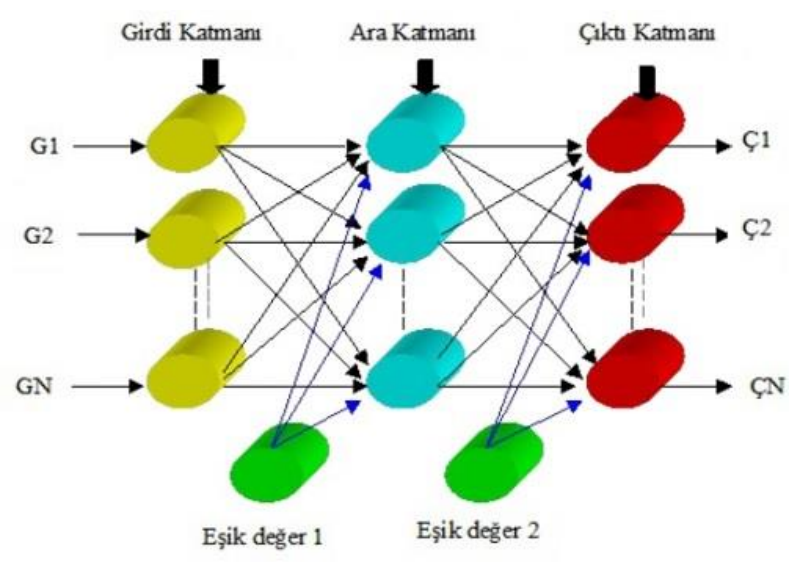

Şekil 4. Çok katmanlı algılayıcıların yapısı (Öztemel, 2016)

Girdi katmanlarından gelen veriler bağlantılar üzerindeki ağırlık değerleri ile belirlenen hesaplama algoritması ile işlem görür. Belirlenen toplama fonksiyonu ile proses elemanına girer proses elemanın içinde yine belirlenen $\mathrm{F}$ (net) fonksiyonundan işlem görerek bir sonraki katmandaki proses elemanlarında işlem görmek 
üzere çıkar. Ara katman yapısı tek veya birden çok katmandan oluşabilir. $\mathrm{Bu}$ katmanlardaki proses elemanlarının sayısı ve katman sayıları tamamen tasarımcının öngörüsüne bağlıdır. Bu topolojiyi belirlemek için bir kural yoktur. Genel olarak deneme-yanılma yolu ile ara katman sayis1 ve bu katmanlardaki proses elemanı sayısı belirlenmektedir.

Ara katmanlarda işlenen veriler çıtı verisini üretmek üzere çıktı katmanına girer bu katman da veriler ara katmandaki prosedüre uygun olarak işlenerek dış dünyaya çıktı olarak verilmek üzere işlenir. Çıktı değerleri üretilir.

Eşik değer proses elemanları ise net verinin 0 (sıfır) olması durumuna karşı sonucunda sıfır çıkmasını önlemek amacı ile konmuş, tüm ara katmanlara ve çıktı katmanına değer gönderir. Proses eleman değeri daima 1 (bir) dir. Ancak ağırlık değeri değişir.

Çok katmanlı algılayıcılar öğretmenli öğrenme stratejisine göre çalışırlar. Yani ağlara eğitim sırasında hem girdiler hem de o girdilere karşılık üretilmesi beklenen çıtıllar gösterilir. Ağın görevi her girdi için o girdiye karşılık gelen çıktıyı üretmektir. Çok katmanlı algılayıcı ağının öğrenme kuralı en küçük kareler yöntemine dayalı Delta öğrenme kuralının genelleştirilmiş halidir. O nedenle öğrenme kuralı genelleştirilmiş Delta kuralı da denmektedir (Öztemel, 2016). İleri doğru hesaplama yapay sinir ağlarının öğrenmesini öğrenme algoritmalarını ele almak gerekirse öncelikle örnek değerleri girdi değerleri $G_{k}$ girer bu girdi değerleri herhangi bir işleme tabi tutulmadan $C_{\text {i }}^{i}$ çıkar.

$C_{k}^{i}=G_{k}$

Girdi katmanından çıkan veri ara katmanlara gönderilir. Girdi katmanı ile ara katman arasında bağlantılar da rasgele atanmış olan ağırlık değerleri bulunur. $\mathrm{Bu}$ ağırlık değerleri ile belirlediğimiz uygun toplama değerine göre işleme girecektir. Ara katman proses elamanın her biri için NET değerin hesaplanması gerekir. NET değer hesaplanan değer belirlenen aktivasyon fonksiyonunda yerine konularak

$N E T_{j}^{a}=\sum_{k=1}^{n} A_{k j} C_{k}^{i}$

şeklinde hesaplanır. Eşik değer proses elemanın çıktı değeri sabit olup daima " 1 " dir. Bu elaman aktivasyon fonksiyonunun oryantasyonunu sağlamak için kullanılmaktadır.
Ara katmanda yapılan işlemlerin tamamı diğer ara katman elemanları için ve çıktı katmanı içinde yapılarak ağın çıktı üretmesi sağlanır. Burada bahsedilen hesaplamaların tümüne ileri doğru hesaplama denmektedir. Geri doğru hesaplama ileri olarak hesaplanan çıktı değeri ile örneğin sonucu arasındaki fark ağın o ağırlıktaki değeri için hatasını ifade etmektedir. Daha önceden de ifade edildiği gibi ağın öğrenmesini proses elemanları arasındaki bağlantılardaki ağırlık değerleri sayesinde gerçekleşmektedir. Geriye doğru hesaplamada da tam olarak uygun ağırlık değerleri aranmaktadır. Geriye doğru hesaplamada proses elemanları arasındaki ağırlık değerleri değiştirilmektedir. Geriye hesaplamada öncelikle beklenen çıktı $B_{m}$ ile ağın çıktısı $C_{m}$ arasındaki farka bakılarak suretiyle hata değeri $E_{m}$ bulunur. Bulunan hata değeri ağırlıklara dağıtılır.

$E_{m}=B_{m}-C_{m}$

$\mathrm{Bu}$ ifade bir proses elemanı için çıktı değeridir. Eğer çıktı olarak birden çok değer varsa bu durumda toplam hatay

$T H=\sqrt{\sum_{m} E_{m}^{2}}$

olarak hesaplamak gerekir. Hata değerleri görüldükten sonra yeni örneği göstermeden önce hatanın dağıtılması gerekmektedir. Bu işlemden iki durum söz konudur: ara katmanla çıktı katmanı arasındaki ağırlıkların değiştirilmesi, ara katmanlar arası veya girdi katmanı ile ara katman arasındaki ağırlıkların değiştirilmesidir. Ara katman ile çıktı katmanı arasındaki ağırlıkların değiştirilmesinde ağırlıkların değişim miktarı,

$\Delta A_{j m}^{a}(t)=\lambda \delta_{m} C_{j}^{a}+\alpha \Delta A_{j m}^{a}(t-1)$

şeklinde hesaplanır. $\mathrm{Bu}$ bağıntıda $\lambda$ öğrenme katsayısı, $\alpha$ momentum katsayısıdır. Bu değerler başlangıçta tasarımeı tarafindan verilen değerlerdir. Bağıntıda tek bilinmeyen değer $\delta_{m}$ hata terimi

$\delta_{m}=f^{\prime}(N E T) \cdot E_{m}$

olarak hesaplanır. Burada yeni ağırlık değerleri ise,

$A_{j m}^{a}(t)=A_{j m}^{a}(t-1)+\Delta A_{j m}^{a}(t)$

şeklinde elde edilir. Eşik değer ünitesi, ağırlıkların değişim miktarında ise (8) eşitliğine benzer şekilde değişmektedir. Eşik değer ünitesinin çıktı 
değeri daima “1” olmasından dolayı formül yeniden düzenlenirse,

$\Delta \beta_{m}^{c}(t)=\lambda \delta_{m}+\alpha \Delta \beta_{m}^{c}(t-1)$

yeni ağırlık değerleri ise

$\beta_{m}^{\mathrm{c}}(t)=\beta_{m}^{\mathrm{c}}(t-1)+\Delta \beta_{m}^{\mathrm{c}}(t)$

şeklindedir. Ara katmanlar arası veya girdi katmanı ile ara katman arası ağırlıkların değiştirilmesinde ise ileriye doğru hesaplamaya benzer bir şekilde hesaplanmaktadır. Proses elemanları arasındaki ağırlıkların değişimi,

$\Delta A_{k j}^{i}(t)=\lambda \delta_{j}^{a} C_{k}^{i}+\alpha \Delta A_{k j}^{i}(t-1)$

olarak elde edilir. Buradaki bilinmeyen tek değer olan hata terimi hesabı,

$\delta_{j}^{a}=f^{\prime}(N E T) \sum_{m} \delta_{m} A_{j m}^{a}$

yeni ağırlık değerleri ise,

$A_{k j}^{i}(t)=A_{k j}^{i}(t-1)+\Delta A_{k j}^{i}(t)$

eşitliğiyle hesaplanır. Eşik değer ünitesi, ağırlıkların değişim miktarında ise (13)'e benzer şekilde değişmektedir. Eşik değer ünitesinin çıktı değeri daima 1 olmasından dolayı formül yeniden düzenlenirse,

$\Delta \beta_{j}^{a}(t)=\lambda \delta_{j}^{a}+\alpha \Delta \beta_{j}^{a}(t-1)$

yeni ağırlık değerleri ise

$\beta_{j}^{a}(t)=\beta_{j}^{a}(t-1)+\Delta A_{j}^{a}(t)$

elde edilir. Belirtilen algoritmalar ile iterasyonlar yapılır ve her seferde ağırlıklar değiştirilerek ağın öğrenmesi sağlanır ağ tüm örnekleri belirtilen hata toleranslarında öğrenene kadar işlem devam ettirilir. Çok katmanlı algılayıcıların tasarımında dikkat edilmesi gereken hususlar: problemin net anlaşılması, örneklerin problemi temsil edebilecek şekilde seçilmesi, girdilerin gösterim şekli, parametre seçimi ve ilk değerlerin atanması, ağın topolojisi, örneklerin ağa sunulma şekli, öğrenme ve durdurma kriterleri şeklinde sıralanır.

\subsection{Polinomlarla Ĕ̆ri Yüzey Uydurma}

Polinomlarla yüzey uydurma yerel jeoit belirmede en çok kullanılan yöntemlerin başında gelmektedir. BÖHHBÜY'ün 42. maddesine göre yerel jeoit oluşturmada bu yönteme göre gerçekleştirilmesi gerekmektedir. $\mathrm{Bu}$ yöntemde yüzey bir fonksiyon ile modellenmeye çalışılmaktadır. Koordinatları bilinen dayanak noktalarının oluşturduğu jeoit yüzeyi sırasıyla $n$. dereceden ortogonal olmayan polinomlar kullanılarak,

$N(x, y)=\sum_{i=0}^{n} \sum_{j=0}^{n} a_{i j} x^{i} y^{j}$

ifade edilebilir (İnal vd., 2003; Abbak, 2017).

Ancak burada kaçıncı derece dereceden polinom kullanılmalıdır sorusu akla gelir. $\mathrm{Bu}$ amaçla, dayanak nokta sayısı göz önünde bulundurularak 1., 2. ve 3. derece polinomlar denenir. Bunlardan karesel ortalama hatası küçük olan çözüm için uygun görülür (Abbak, 2017). Yönetmeliğe göre karesel ortalama hata $5 \mathrm{~cm}$ üstünde çıkması halinde çözüm aranmaz bunun yerine uyuşumsuz ölçüler testi uygulanarak hatalı ölçü araştırması yapılır. Eğer varsa bu değer atılarak tekrar dengeleme yapilır. Ortalama hata $5 \mathrm{~cm}$ 'nin altında ise $t$ (student) dağılımına göre parametrelere anlamlılık testi uygulanır. Anlamlı parametrelerle yüzey modeli oluşturulur.

Noktaların yatay konumları 6 ve 7 basamaklı olduğundan en küçük kareler çözümünde katsayılar matrisinin elemanları çok büyük sayılardan oluşmakta ve normal denklem matrisinin kondisyonunu bozmaktadir. $\mathrm{Bu}$ durumda yatay koordinat değerlerini ölçeklendirmek üzere,

$x_{i}^{\prime}=\frac{x_{i}-x_{0}}{1000} \quad y_{i}^{\prime}=\frac{y_{i}-y_{0}}{1000}$

eşitliği kullanılır. Ölçeklendirme sonrasında elde edilen koordinatlar ile en küçük kareler yöntemine göre çözüm sağlanarak model oluşturulur. Test noktaları üretilen fonksiyonda hesaplanarak üretilen sonuçla olması gereken gerçek değer arasındaki farka bakılarak test noktaları için karesel ortalama hata hesaplanır. Modelin test verileri için ürettiği sonuç modelin başarısını (doğruluğunu) gösterir.

\section{Sayısal Uygulama}

\section{1. Çalışma Alanı}

Belçika'nın kuzey doğusunda yaklaşık olarak $50.2^{\circ}<\varphi<50.7^{\circ} ; \quad 5.4^{\circ}<\lambda<6.1^{\circ} \quad$ coğrafi sinırlar arasında kalan engebeli bölge çalışma alanı olarak seçilmiştir. Bölge yaklaşık $50 \mathrm{~km}$ x $56 \mathrm{~km}$ boyutlarında olup yüzölçümü $2765 \mathrm{~km}^{2}$ dir. Çalışma alanında yükseklik değerleri $150 \mathrm{~m}$ ile 
$550 \mathrm{~m}$ arasında değişmektedir. Söz konusu bölge, jeoit ve topografya değişiminin fazla olması nedeniyle çalışma alanı olarak seçilmiştir (Şekil 5). Araştırma konusu farklı yoğunluktaki verilerin jeoit modeline etkisi olduğundan sik ve yüksek doğruluklu veriler ancak bu bölgeden temin edilebilmiştir.

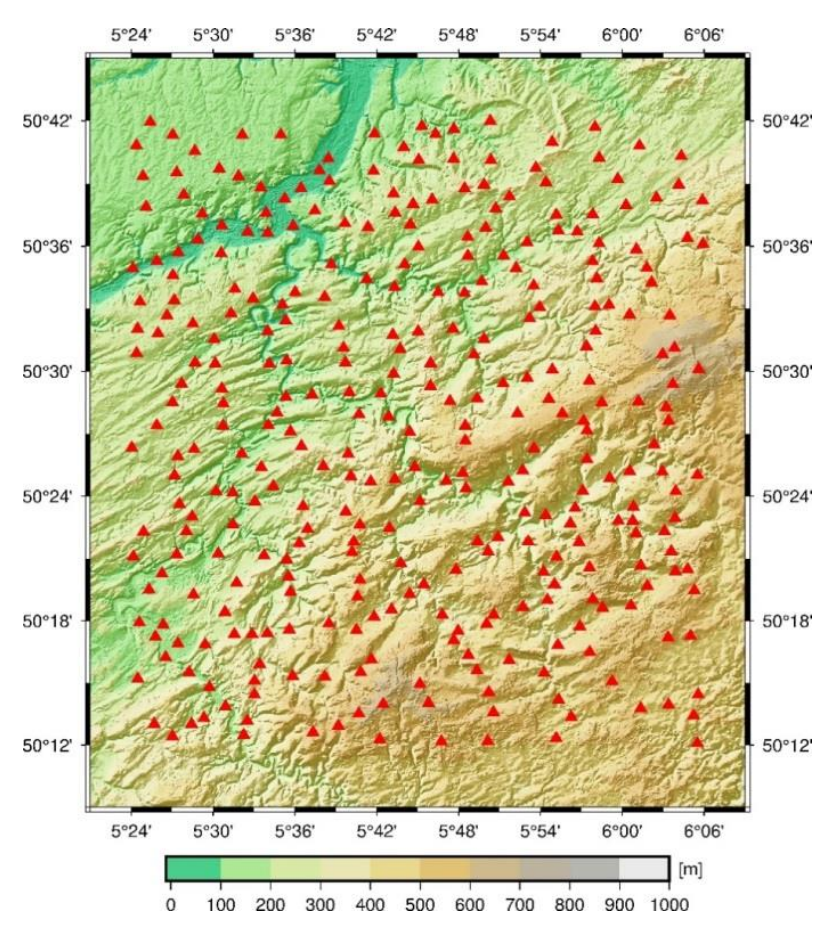

Şekil 5. Çalışma bölgesi ve uygulama noktaları

\subsection{Veriler}

Çalışma bölgesine ait GNSS-nivelman nokta verileri Belçika Ulusal Coğrafya Enstitüsünden elde edilmiştir. Çalışma bölgesinde 326 adet GNSS-nivelman noktası bulunmaktadır. Veriler; noktaların projeksiyon koordinatları ( $x$ ve $y$ ), elipsoidal yüksekliğgi $(h)$ ve ortometrik yükseklik $(H)$ değerlerinden oluşmaktadır. Elipsoidal ve ortometrik yüksekliklerin doğruluğu $1 \mathrm{~cm}$ olduğundan noktaların jeoit yüksekliğinin doğruluğu 1-2 cm seviyesindedir (Verbeurgt, 2018). Verilere göre çalışma alanında jeoit yüksekliği değişimi $1,764 \quad \mathrm{~m}$ olarak hesaplanmıştır. Veriler, çalışmada eğitim ve test verileri olarak ayrıştırılarak jeoit modeli belirlenecektir.

\subsection{Araștırma}

$\mathrm{Bu}$ çalışmanın amacı ileri beslemeli hata geri yayılımlı yapay sinir ağlarının jeoit yüksekliğini tahminindeki performansını araştırmaktır. $\mathrm{Bu}$ amaçla, çalışma bölgesindeki veriler belirli kombinasyonlarla test ve eğitim seti olarak ayrıştırılarak yapay sinir ağlarının ürettiği sonuçlar, yönetmelikte bahsedilen polinomal yöntem ile karşılaştırılacak ve sonuçlar irdelenecektir (Tablo 2).

İlk deneyde tüm verilerin yaklaşık \%22'si test verisi olacak şekilde 256 adet eğitim ve 70 adet test verisi olarak seçildi (Şekil 6a). Eğitim verileri çalışma alanının tamamını kapsayacak şekilde homojen dağılmış olmasına dikkat edildi. İkinci

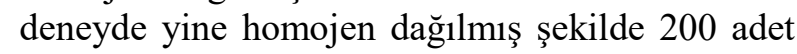
eğitim 126 adet test verisi seçildi (Şekil 6b). Bu dağılımın seçilme nedeni yönetmeliğin 42 . maddesi gereğince en az sayıda eğitim verisinde üretilerek sonuçların görülmesi amaçlanmıştır. Üçüncü, dördüncü ve beşinci deneyde yine homojen dağılmış olmak şartıyla eğitim verilerinin kademeli olarak azaltılması, modellerin başarısına olan etkisini görmek amacı ile seçildi (Şekil 6c, 6d, 6e). Altıncı deneyde ise verilerin homojen dağılmamış durumda yöntemlerin ne doğrulukta sonuçlar ürettiğini görmek amaçlanmıştır. Çalışma alanının ortasındaki 133 nokta eğitim verisi olarak seçilmiş bu noktaların dışındaki 193 adet nokta test verisi olarak kullanılmıştır (Şekil 6f).

Yapay sinir ağ modelini ve polinomal eğri yüzey modelini oluşturmak için MATLAB 2016 programlama dili kullanılmıştır. Polinomal eğri yüzey modelini oluşturmak için MATLAB'ın program geliştirme ortamında hazır bir fonksiyon kullanılmaksızın bir yazılım geliştirilmiştir. Diğer yandan ileri beslemeli hata geri yayımlı yapay sinir ağı için MATLAB'ın yapay sinir ağları modülünde (Neural Network Toolbox) hazır fonksiyonlar(network) kullanılarak programlanmıştır.

Polinomal eğri yüzey oluştururken öncelikle çalışma alanın en iyi uyan polinomun derecesi araştırıldı. Optimum çözümün 4. dereceden polinom olduğu görüldü. Parametre testi ile anlamsız parametreler atılarak jeoit modeli oluşturuldu.

Yapay sinir ağlarında model oluşturmada belirli bir kural yoktur. Ara katman sayıları, ara katmanlardaki proses elemanı sayısı, öğrenme algoritmas1, toplama fonksiyonu, iterasyon sayıs1 gibi değişkenler deneme- yanılma yoluyla belirlenebilmektedir. $\mathrm{Bu}$ nedenle verilerin çözümünde çok sayıda deneme yapılarak hata değeri en aza indirgenir. Bu denemelerde en az 1 en çok 10 adet ara katman sayısı belirlenmiştir. Ara katmanlardaki nöron sayısı olarak en az 10 en çok 700 olarak denemeler yapılmıştır. 


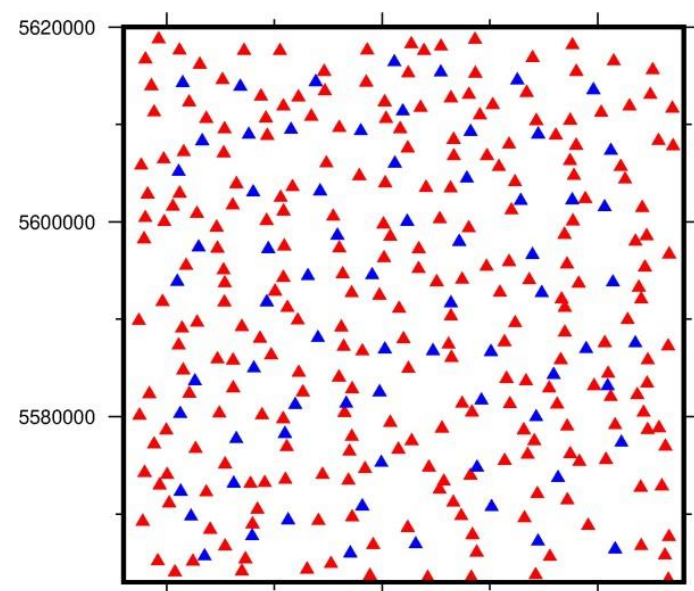

a) Deney 1

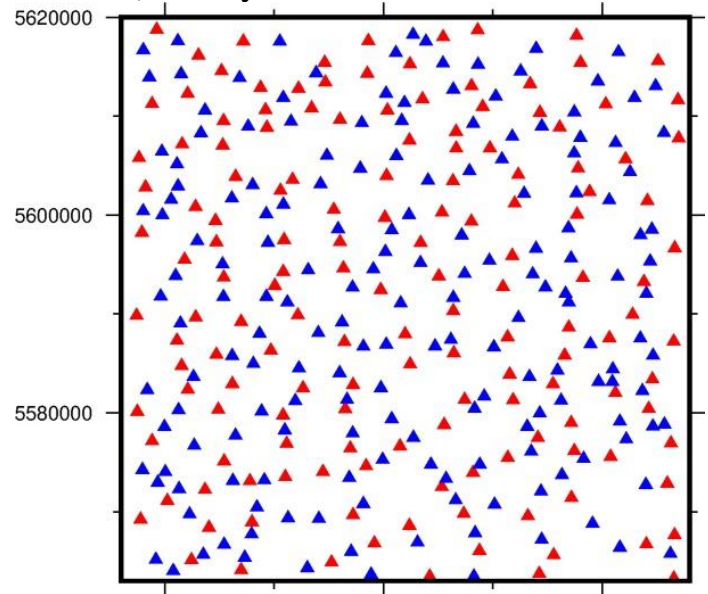

c) Deney 3

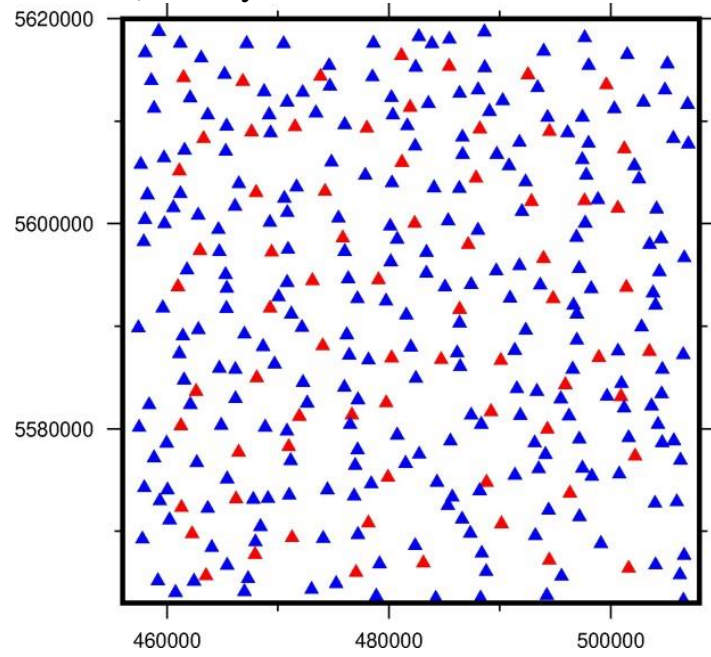

e) Deney 5

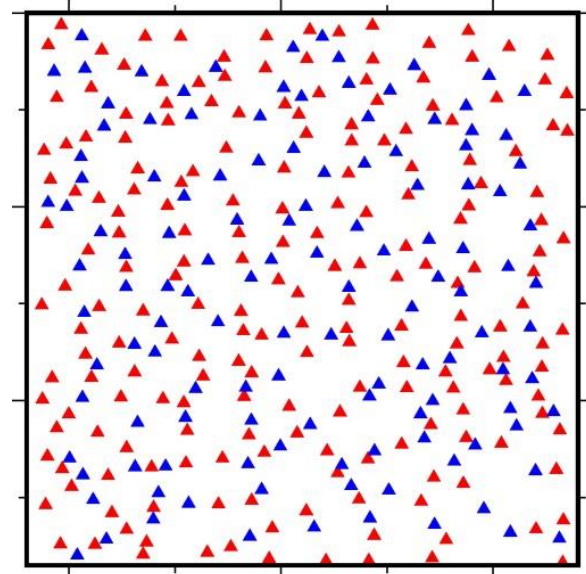

b) Deney 2

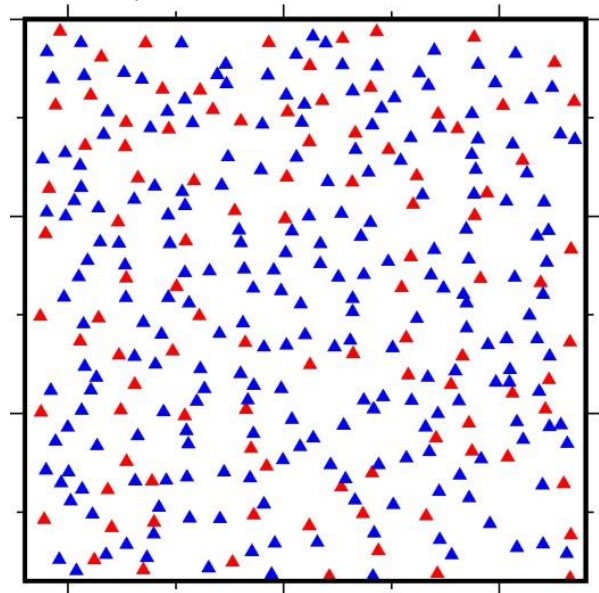

d) Deney 4

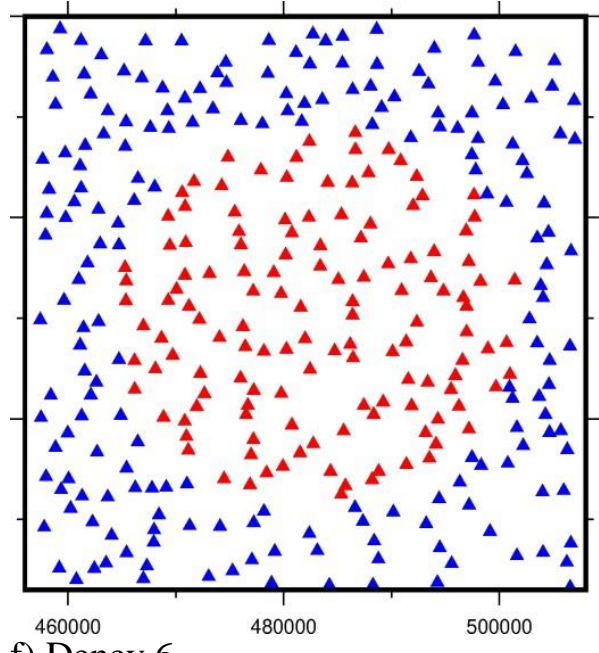

f) Deney 6

Şekil 6. Deneylerdeki noktaların coğrafi dağılımı (kırmızı: eğitim, mavi: test verilerini göstermektedir)

Tablo 2. Deneylerdeki eğitim ve test verilerinin sayısı

\begin{tabular}{|l|l|l|l|}
\hline Deney No & Eğitim Veri Sayısı & Test Veri Sayısı & Nokta Dağı̆ımı \\
\hline 1 & 256 & 70 & Homojen \\
\hline 2 & 200 & 126 & Homojen \\
\hline 3 & 150 & 176 & Homojen \\
\hline 4 & 100 & 226 & Homojen \\
\hline 5 & 70 & 256 & Homojen \\
\hline 6 & 133 & 193 & Homojen değil \\
\hline
\end{tabular}


$\mathrm{Bu}$ amaçla ağın en iyi öğrenme modeli olarak 2 ara katmanda ve ara katman proses elemanı sayıları 20 ve 30 olarak bulunmuştur. Oluşturulan eğitim setleri programlara girdi olarak verilerek öncelikle uygun model araştırması yapılmış ve optimum modele eğitim verileri için karesel ortalama hatası hesaplanmıştır. Aynı modellere test verileri de sunularak bu noktalar için sonuç üretmesi istenmiştir. Üretilen ile gerçek sonuçlar irdelenerek en iyi ve en kötü tahmin değerleri ile test setinin karesel ortalama hatası hesaplanmıştır (Tablo 3).

Tablo 3. Yapay sinir ağları ve polinomal modellerin karşılaştırması (cm)

\begin{tabular}{|l|l|l|l|l|l|l|l|l|l|l|}
\hline \multirow{2}{*}{$\begin{array}{c}\text { Deney } \\
\text { No }\end{array}$} & $\begin{array}{c}\text { Eğitim } \\
\text { seti } \\
\text { adedi }\end{array}$ & $\begin{array}{c}\text { Test } \\
\text { seti } \\
\text { adedi }\end{array}$ & $\mathrm{KOH}_{\text {Eğitim }}$ & $\mathrm{KOH}_{\text {Test }}$ & $\begin{array}{c}\text { Test seti } \\
\text { maksimum } \\
\text { hata }\end{array}$ & $\begin{array}{c}\text { Test seti } \\
\text { minimum } \\
\text { hata }\end{array}$ & $\mathrm{KOH}_{\text {Eğitim }}$ & $\mathrm{KOH}_{\text {Test }}$ & $\begin{array}{c}\text { Test seti } \\
\text { maksimum } \\
\text { hata }\end{array}$ & $\begin{array}{c}\text { Test seti } \\
\text { minimum } \\
\text { hata }\end{array}$ \\
\hline 1 & 256 & 70 & 0.53 & 0.92 & 2.57 & 0.02 & 2.24 & 2.07 & 6.38 & 0.09 \\
\hline 2 & 200 & 126 & 0.68 & 0.99 & 3.36 & 0.01 & 2.23 & 2.20 & 6.47 & 0.01 \\
\hline 3 & 150 & 176 & 0.65 & 1.00 & 3.25 & 0.01 & 2.11 & 2.32 & 5.80 & 1.25 \\
\hline 4 & 100 & 226 & 0.82 & 1.12 & 3.40 & 0.00 & 2.29 & 2.26 & 7.26 & 0.00 \\
\hline 5 & 70 & 256 & 0.90 & 1.55 & 5.53 & 0.01 & 2.01 & 2.69 & 11.86 & 0.02 \\
\hline 6 & 133 & 193 & 0.53 & 5.99 & 23.08 & 0.04 & 1.52 & 30.13 & 169.70 & 0.02 \\
\hline
\end{tabular}

\section{Tartışma ve Sonuç}

$\mathrm{Bu}$ çalışmada yapay sinir ağları ve polinomal eğri yüzey uydurma teori ve kavramları açılanmış, yerel jeoit belirleme konusunda çözümler araştırılmıştır. Sayısal uygulamada $2765 \mathrm{~km}^{2}$ lik bir alan seçilmiş, bu alanda farklı nokta sayıları ile jeoit modellenmiş ve modellerin doğrulukları araştırılmıştır.

Deney 1'de sonuçlardan anlaşıldığ yöntem de yüksek doğruluklu modeller üretmiştir. Ancak yöntemler birbirlerine göre kıyaslanırsa yapay sinir ağı daha iyi sonuç ürettiği görülmüştür.

Deney 2'de yönetmelik dikkate alınarak eğitim verileri minimumda tutulmuş, yöntemlerin modelleri iyi sonuçlar vermiş ve yönetmelik hata sınırları içinde kalmıştır. Bu deneyde de yapay sinir ağı modeli polinomal yönteme oranla daha iyi sonuç üretmiş̧ir.

Deney 3 , deney 4 ve deney 5 'de eğitim noktaları kademeli olarak azaltılması modellerin yüzeyleri tasvir gücünde azalma yaşandığı göstermiştir. Sonuçlar yönetmelik sınırları içerisinde kaldığı görülmüş̧ür. Ancak sonuçların bu denli istikrarlı kalması ve ani değişimlerin yaşanmamasının temel nedeni eğitimde kullanılan nokta verilerinin yüksek doğruluklu olması ve noktaların homojen olarak dağılmış olmasıdır. Yöntemlerin kıyaslamasında ise yapay sinir ağlarının yine çok iyi sonuçlar vermiştir.
Deney 6'da ise eğitim nokta verilerinin homojen dağılmaması durumunda yöntemlerin üreteceği sonuçlar araştırılmıştır. Polinomal yöntem ve yapay sinir ağlarında örnekleme noktalarının problemin tamaminı tasvir eder nitelikte olmas1 gerekmektedir. Bu deneyde polinomal yöntemin modelleyemediği ve model yapısının bir anda bozulduğu belirlenmiştir. Diğer yandan yapay sinir ağlarında da model yapısının bozulduğu görülmüştür. Ancak polinomal yönteme oranla daha iyi sonuçlar üretmiş ve model alanı dışındaki noktalarda dahi güvenilir bir sonuç elde etmiş̧ir.

Tüm deneylerin sonuçlarından yola çıarak yapilan denemeler sonucunda ileri beslemeli geri yayılımlı yapay sinir ağlarının jeoit belirlemede polinomal yönteme oranla çok daha iyi sonuçlar ürettiği anlaşılmıştır.

Yapay sinir ağları ürettiği bu sonuçlar günümüzde popüler bir teknoloji olmasının sebebini kanıtlar niteliktedir. Bunlara rağmen uygulamada da görüldügü üzere çoğu parametre deneme-yanılma yöntemi ve kişisel deneyimlerle elde edilmektedir. Bunu gündelik hayatta kullanmak için kişinin yapay sinir ağ 1 konusunda uzman olmas1 gerekmektedir. $\mathrm{Bu}$ problemi aşabilmek için günümüz teknolojisi ile deneme-yanılma yöntemlerini kendisi otonom olarak gerçekleştirerek kendi kendine öğrenebilen ve optimum çözümü üretebilecek yazılımlar ile son kullanıcının hizmetine sunulabilir. Ayrıca yapay sinir ağların öğrenmesi sırasında oluşan ağır işlem yükü ve öğrenme sürelerinin uzunluğu sebebi ile 
sonuçların üretilmesi donanıma bağımlı hale getirmektedir. Hızlı ve anlık çözülmesi gereken problemlerde yapay sinir ağlarının diğer yöntemlere oranla yetersiz kalacağı bir diğer zayıflık olarak değerlendirilmektedir. Ancak sınırlı sayıdaki verilerde dahi ileri beslemeli geri yayılımlı yapay sinir ağlarının ne denli doğru sonuç ürettiği görülmektedir. Belirtilen öneriler 1şığında gerekli yazılımlar üretilebilirse jeodezik projelerde yapay sinir ağları bir seçenek olarak kullanılabilir.

\section{Kaynaklar}

Abbak, R. A., (2017) Fiziksel Jeodezi Teori ve Uygulama, Atlas Akademi Yayıncılık, Konya.

Arslan, O., Kurt, O., Konak, H., (2007) Yapay Sinir Ağlarının Jeodezide Uygulamaları Üzerine Öneriler, 11. Türkiye Harita Bilimsel ve Teknik Kurultay1, 2-6 Nisan 2007, Ankara.

Aşık, E., (2013) Lokal Jeoit Belirlemede Yapay Sinir Ağları ve Kriging Yönteminin Karşılaştırılması, Yüksek Lisans Tezi, Afyon Kocatepe Üniversitesi Fen Bilimleri Enstitüsü, Afyon.

Beale, M. H., Hagan, M. T. Demuth, H. B., (2010) Neural Network Toolbox 7 User's Guide. The MathWorks Inc., Natick, MA.

Çakır, L., (2015) Sayısal Yükseklik Modelinde Klasik Ve Esnek Hesaplama Yöntemlerinin Karşılaştırılması, 15. Türkiye Harita Bilimsel ve Teknik Kurultay1, 25-28 Mart 2015, Ankara.
Çorumluoğlu, Ö., Özbay, Y., Kalaycı, İ., Şanlıoğlu, İ., (2005) GPS Yüksekliklerinden Ortometrik yüksekliklerin elde edilmesinde Yapay Sinir Ağı (YSA) Tekniğinin kullanımı, 2. Mühendislik Ölçmeleri sempozyumu, 23-25 Kasım 2005, İstanbul.

Graupe, D., (2007) Principles of Artifical Neural Networks, World Scientific Publishing, Singapore.

İnal, C., Turgut, B. ve Yiğit, C., Ö., (2003) Lokal Alanlarda Jeoit Ondülasyonunun Belirlenmesinde Kullanılan Enterpolasyon Yöntemlerinin Karşılaştırılması, Selçuk Üniversitesi Jeodezi ve Fotogrametri Mühendisliğinde 30, Yıl Sempozyumu, Ekim, Konya, Bildiriler Kitab1, 97-106.

Kaftan, İ., (2010) Batı Türkiye Gravite ve Deprem Katalog Verilerinin Yapay Sinir Ağları ile Değerlendirilmesi, Doktora Tezi, Dokuz Eylül Üniversitesi, Fen Bilimleri Enstitüsü, İzmir.

Öztemel, E., 2016, Yapay Sinir Ağları, Papatya Bilim Üniversite Yayıncılığı, İstanbul.

Patan, K., 2008, Artificial Neural Networks for the Modelling and Fault Diagnosis of Technical Processes, Springer, London-New York.

Verbeurgt, J. (2018) Kişisel görüşme, Belçika Coğrafya Enstitüsü, Brüksel.

Yılmaz, M., (2012) Jeodezik Nokta Hız Kestiriminde Yapay Sinir Ağlarının Kullanılabilirliği, Doktora Tezi, Afyon Kocatepe Üniversitesi, Fen Bilimleri Enstitüsü, Afyonkarahisar 